NBER WORKING PAPER SERIES

\title{
SHOCKS, INSTITUTIONS AND SECULAR CHANGES IN EMPLOYMENT OF OLDER INDIVIDUALS
}

\author{
Richard Rogerson \\ Johanna Wallenius \\ Working Paper 28914 \\ http://www.nber.org/papers/w28914
NATIONAL BUREAU OF ECONOMIC RESEARCH
1050 Massachusetts Avenue
Cambridge, MA 02138
June 2021

We thank Mark Bils and Nir Jaimovich for comments, as well as conference participants at the NBER Macro Annual Conference and seminar participants at the Cleveland Fed. Wallenius thanks the Knut and Alice Wallenberg Foundation for financial support. The views expressed herein are those of the authors and do not necessarily reflect the views of the National Bureau of Economic Research.

At least one co-author has disclosed additional relationships of potential relevance for this research. Further information is available online at http://www.nber.org/papers/w28914.ack

NBER working papers are circulated for discussion and comment purposes. They have not been peer-reviewed or been subject to the review by the NBER Board of Directors that accompanies official NBER publications.

(C) 2021 by Richard Rogerson and Johanna Wallenius. All rights reserved. Short sections of text, not to exceed two paragraphs, may be quoted without explicit permission provided that full credit, including $\odot$ notice, is given to the source. 
Shocks, Institutions and Secular Changes in Employment of Older Individuals

Richard Rogerson and Johanna Wallenius

NBER Working Paper No. 28914

June 2021

JEL No. E24,J21,J26

\begin{abstract}
$\underline{\text { ABSTRACT }}$
Employment rates of males aged 55-64 have changed dramatically in the OECD over the last 5 decades. The average employment rate decreased by more than 15 percentage points between the mid-1970s and the mid-1990s, only to increase by roughly the same amount subsequently. One proposed explanation in the literature is that spousal non-working times are complements and that older males are working longer as a result of secular increases in labor supply of older females. In the first part of this paper we present evidence against this explanation. We then offer a new narrative to understand the employment rate changes for older individuals. We argue that the dramatic U-shaped pattern for older male employment rates should be understood as reflecting a mean reverting low frequency shock to labor market opportunities for all workers in combination with temporary country specific policy responses that incentivized older individuals to withdraw from market work.
\end{abstract}

\author{
Richard Rogerson \\ Department of Economics \\ JRR Building Room 292 \\ Princeton University \\ Princeton, NJ 08544 \\ and NBER \\ rdr@princeton.edu \\ Johanna Wallenius \\ Department of Economics \\ Stockholm School of Economics \\ Box 6501 \\ 11383 Stockholm \\ Sweden \\ johanna.wallenius@hhs.se
}




\section{Introduction and Background}

Against a backdrop of lower fertility and increased longevity, employment levels of older individuals have become an important concern for policy makers in advanced economies. The motivation for this paper derives from Figure 1, which plots the mean employment rate (i.e., employment divided by population) for males aged 55-64 for a balanced panel of 14 OECD economies for which there is consistent data from 1976 forward: ${ }^{1}$

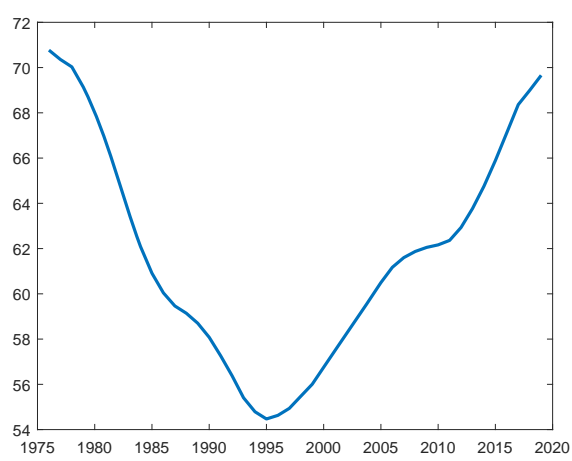

Figure 1: Mean Emp/Pop Rate, Males 55-64

The changes reflected in this figure are dramatic: between 1976 and 1995 the mean employment rate for this group dropped by more than fifteen percentage points, only to increase by almost this same amount between 1995 and 2019. What is all the more remarkable about this figure is that the employment rate for older male workers had been declining for many decades prior to the 1970s, so that the increase since 1995 is reversing a decades long period of declining employment

\footnotetext{
${ }^{1}$ The countries represented in this figure are Australia, Canada, Finland, France, Germany, Ireland, Italy, Japan, Netherlands, Norway, Portugal, Spain, Sweden and the US.
} 
rates for these workers. ${ }^{2}$

Understanding the factors that account for the dramatic changes in this figure is of interest in its own right in the broader context of the desire to understand the forces that shape labor supply. But it is of special importance for policy makers who want to forecast trends into the future and design appropriate policies going forward.

While the qualitative pattern depicted in Figure 1 is common to almost all of the 14 countries considered, there is considerable heterogeneity in the quantitative features of the U-shape across countries. Figure 2 plots five year moving averages for the employment to population ratios for males aged 55-64 for each of the 14 countries.

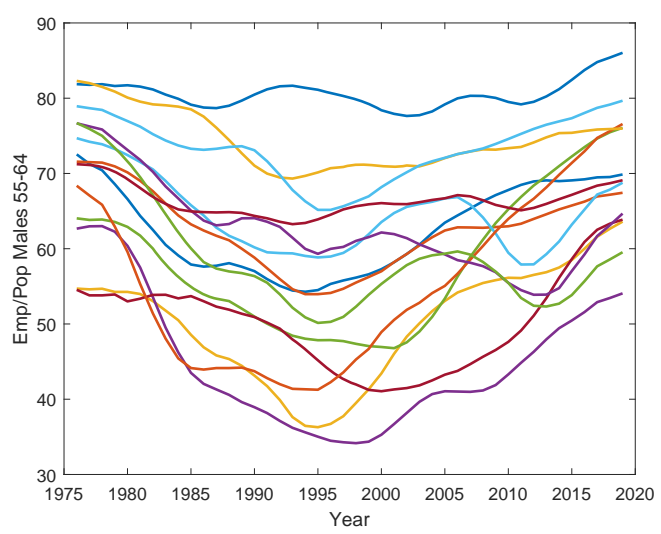

Figure 2: Emp/Pop Rate for Males 55-64 in 14 Countries

A complete understanding of the dynamics in Figure 2 will ultimately require

\footnotetext{
${ }^{2}$ We of course are not the first ones to note this pattern. A recent issue of the NBER series on Social Security Programs and Retirement Around the World (Coile et al (2019)) was entirely devoted to this issue.
} 
detailed analyses at the country level. ${ }^{3}$ But the similarity of the qualitative pattern across countries suggests that the effort to understand the country specific evolutions might usefully be framed within a common unifying framework. The main goal of this paper is to put forth a broad narrative that can serve to sketch this framework. Developing the main elements of our narrative reflects three features of our analysis: it contrasts outcomes across countries, it studies changes over a relatively long time period, and it seeks to understand changes in employment rates for older workers in the context of broader changes in the labor market.

Our narrative builds on the earlier literature on shocks and institutions (see, e.g., Bruno and Sachs (1985), Krugman (1994), Ljungqvist and Sargent (1998), Mortensen and Pissarides (1999), and Blanchard and Wolfers (2000)). Three facts motivated this literature. First, labor market conditions as proxied by the unemployment rate worsened in almost all OECD economies starting in the 1970s, and persisted throughout much of the 1980s. Second, the extent of deterioration varied significantly across economies. Third, there were persistent differences in labor market institutions across countries.

This literature proposed the following broad narrative: the overall worsening of labor market outcomes was due to a common shock (or series of shocks), and the variation in outcomes across economies arose because heterogeneous institutions differentially affected the propagation of the common shock within each economy. ${ }^{4}$

\footnotetext{
${ }^{3}$ The NBER series on Social Security Programs and Retirement Around the World promotes exactly this type of work.

${ }^{4}$ The common shock is typically viewed as reflecting some combination of the oil shocks of the 1970s and the more persistent processes of globalization and skill biased technical change. The
} 
While some economies were plausibly more exposed to the shock, and institutions were not literally constant over time at their 1960s levels, the core message of the shocks and institutions literature was that a common shock propagated by heterogeneous institutions provided a good account for the cross-sectional heterogeneity in labor market evolutions in the 1970s and 1980s. Notably, because this literature focused on aggregate outcomes, it did not single out the labor market outcomes of any particular demographic group.

Similar to the earlier shocks and institutions literature, a key component of our proposed narrative is a common shock that negatively affected opportunities of all workers between 1970 and the mid 1990s. Given the stylized fact from the business cycle literature that young and old workers experience larger fluctuations than prime aged individuals (see, e.g., Clark and Summers (1981) and Gomme et al (2004)), it is perhaps not surprising that older individuals might also experience larger responses to low frequency shocks. Beyond the business cycle evidence, a shock that favors new skills that complement technological change will plausibly have larger effects on older workers since they are more likely to have skills that lose value and are less able to learn new skills.

But differently than the earlier shocks and institutions literature, our narrative also emphasizes heterogeneous responses in institutions as key to understanding the heterogeneity in responses shown in Figure 2. Specifically, during the 1970s and 1980s, many countries instituted substantial expansions of what we will refer to as the "shadow social security system," thereby encouraging and accommodat-

key institutions were typically seen as Unemployment Insurance (UI), wage-setting practices, and Employment Protection Legislation (EPL). 
ing the effective retirement of workers prior to reaching "normal" retirement age and entry into the formal social security system. Because many of these provisions were cut back following the mid 1990s, they constitute an additional U-shaped driving force affecting older workers in a subset of countries.

Summarizing, we argue that the dynamics in Figure 1 should be understood as a combination of (at least) three processes. The first is a slow moving trend component, reflecting the net effect of secular changes such as income, health, life expectancy, education and the nature of work. A second process captures the effect of a low frequency but mean reverting negative shock to labor market opportunities that affected all age groups, though more so in the case of older workers. ${ }^{5}$ This process gives rise to U-shaped dynamics like those in Figure 1. The third process is a temporary shock to institutional features in a subset of countries that served to significantly amplify the effect of the common shock on workers aged 55-64 in these countries. We argue that this third process is key to understanding both the magnitude of the changes in Figure 1 and the heterogeneity in Figure $2 \cdot{ }^{6}$

\footnotetext{
${ }^{5}$ We infer the presence of a mean reverting shock by observing common low frequency movements in employment rates for males of all age groups. The original shocks and institutions literature focused on the period prior to 2000 and so did not say anything about mean reversion. To the extent that globalization and skill biased technical change are ongoing processes, mean reversion may seem counterintutive. However, if one thinks of the economy as adjusting to the use of a new technology, the adjustment process can lead to dynamics that mimic those associated with a low frequency mean reverting shock relative to trend. (See, for example Hornstein and Krusell (1996) and Greenwood and Yorukoglu (1997).) For our purposes, the common shock will also potentially reflect changes in overall economic policies that affect economic activity. An example would be product market regulation. This is potentially relevant for understanding some of the dynamics in Europe.

${ }^{6}$ Several countries have also implemented reforms of their formal Social Security programs in the late 1990s and 2000s. While not the focus of our analysis, these may have also contributed to the rise in employment rates in some countries and might be thought of as a fourth process,
} 
By viewing the dynamics in Figure 1 as largely reflecting deviations from a slow moving trend, our narrative stands in contrast to much work studying the employment of older males. At the risk of oversimplifying, textbook discussions of this decades long decline stress two key driving forces: the expansion of social security programs and secular increases in incomes. ${ }^{7}$ To the extent that most advanced economies had instituted the key features of their Social Security programs by the early 1960s, explanations for the continued decline in employment rates of older males have tended to highlight ongoing increases in income.

However, it has also been recognized that the increases in income were happening alongside other secular trends that might plausibly increase employment rates for older males, including for example, improvements in health, increases in life expectancy, and increases in educational attainment. ${ }^{8}$ But viewed from the perspective of underlying secular trends, the widespread trend reversal following the mid 1990s is puzzling: none of the secular driving forces display trend breaks around this time; nor were there widespread changes to (formal) Social Security programs. ${ }^{9}$

though some of these changes might best be viewed as part of the process of undoing the earlier expansion of the shadow social security system. See the various contributions in Borsch-Supan and Coile (2020) for more detail on these changes and an assessment of their effects.

${ }^{7}$ There is good reason to believe that the effect of income becomes smaller as an economy becomes richer. First, from a theoretical perspective subsistence constraints make income effects larger at lower levels of income. Vandenbroucke (2009) shows that this was important for understanding the changing distribution of hours worked across the wage distribution in the US in the first half of the 1900s. But almost all wage gains in the US since 1980 have gone to those with college education, and if anything males in this group have increased their absolute and relative level of market work.

${ }^{8}$ As one example, Burtless (2013) argues that higher educational attainment accounts for a significant part of the increase in employment rates for older males in the US since the mid 1990s.

${ }^{9}$ See for example, the various chapters in Coile et al (2019) for analyses that find little 
For researchers wanting to connect the dynamics in Figure 1 to secular trends, this has motivated a search for new trend factors that might have only become important during the 1990s. One such promising candidate was first proposed by Schirle (2008). The core mechanism in this narrative is that exogenous increases in employment rates for older females would decrease retirement incentives for older males if leisure times of couples are complements. It also holds that beginning in the 1960s, young women entered the labor market with different expectations regarding careers, leading to very significant cohort effects for female employment rates by age. Because the cohort of women that turned 20 in 1960 would turn 55 in 1995, it would be around this time that males aged 55-64 would be increasingly likely to be married to a female who was engaged in market work. In the first part of this paper we present new evidence regarding this narrative and argue that it is unlikely to be a dominant factor in accounting for the pattern shown in Figure 1. In fact, our evidence implies that rather than being a solution to the puzzle, the sharp increase in average employment rates for older females after the mid 1990s is just another piece of the puzzle that needs to be explained. Because the key elements of our narrative are gender neutral, it explains why both older males and females display large changes in employment rates in the mid 1990s.

A key question for policy makers is to forecast future employment rates of older individuals holding policy settings fixed. Our narrative has an important cautionary message for policy makers that would like to use the information in Figure 1 to answer this question. Because we view much of the movement in explanatory power in these factors for the mid 1990s reversal in older males' employment rates. 
Figure 1 as reflecting responses to mean reverting aggregate conditions and the temporary expansion and contraction of policy settings that directly impact the employment rates of older individuals, isolating the relevant trend component for predicting future changes holding policy fixed will require methods to isolate the trend components from the other factors at work.

The literature that our work relates to is too large to attempt to survey. But we single out two sources of particular interest. The first is the volume edited by Kohli et al (1991), that summarizes the expansion of the shadow social security systems during the 1970s and 1980s in a large set of countries. The second source is the many volumes produced by the NBER Program on Social Security Programs and Retirement Around the World, which has sought to provide ongoing comparable country level studies on a variety of issues; the two most recent volumes (Coile et al (2019) and Borsch-Supan and Coile (2020) are particularly relevant. While our analysis touches on many issues that this series has addressed, we nonetheless believe our narrative offers a distinct perspective via its connection to the earlier shocks and institutions literature, its focus on mean reverting factors and its emphasis on analyzing the outcomes for older individuals in the context of broader labor market developments.

While our broad brush stroke approach serves a useful purpose in organizing our thinking about the forces that shape the dynamics shown in Figures 1 and 2, it also has some obvious limitations. First, we focus almost exclusively on highly aggregated data. Second, we do not complement our narrative with any quantitative model based framework. As we discuss in the conclusion, important next 
steps in this research agenda are to document the facts at a more disaggregated level and to carry out rigorous country-level structural analyses that fully reflect the relevant context for older workers. ${ }^{10}$

We also offer one cautionary note to the reader. Although the US is included in our sample of countries, we in no way focus on the particular case of the US. We highlight this because the US is the subject of much study and it turns out that the US displays some but not all of the properties that hold more generally for other countries. ${ }^{11}$ With this in mind, we caution the reader from interpreting all of our results from the perspective of a US benchmark.

An outline of the paper follows. In Section 2 we discuss the key data sources and provide additional documentation regarding the key motivating fact displayed in Figure 1. Section 3 presents evidence on the narrative stressing older female employment rates as the driving force behind the trend reversal found in Figure 1. Section 4 presents our alternative narrative and provides evidence in support of its key elements. Section 5 briefly overviews the evolution of the employment rate for individuals aged 65-69 and discusses how they fit with our proposed narrative. Section 6 concludes and discusses directions for future research on this issue.

\section{Data}

The main data for the second part of our analysis comes from the OECD and relates to employment to population ratios by age and gender over the period

\footnotetext{
${ }^{10}$ We note that our discussants have taken a step in this direction by analyzing patterns in the micro data for Germany and the US. See also the various contributions in the NBER series on Social Security Programs and Retirement Around the World, including in particular the most recent volume, Borsch-Supan and Coile (2020).

${ }^{11}$ See Costa (1998) for an extensive discussion and analysis of the history of retirement in the US context.
} 
1960-2019. ${ }^{12}$ The sample of countries that we study consists of 22 "advanced" economies, 16 from Europe, two from North America and four from Australasia. The year at which data first becomes available varies across countries, ranging from 1960 to 1994. Data availability also differs depending upon which age group we consider. In particular, there is less availability of data that considers employment to population ratios for each of the 55-59 and 60-64 age groups than for the 55-64 age group. ${ }^{13}$ While it is of interest to consider the 55-59 and 60-64 age groups separately, in the interests of space our core analysis will focus exclusively on the 55-64 group. In a later section we will briefly examine the 65-69 age group.

For much of our analysis we will be interested in a balanced panel and so will consider a sequence of balanced panels that differ by starting date and hence have different numbers of countries. Importantly, the key messages are robust across these different samples. Our smallest but longest panel begins in 1970 and includes Australia, Finland, Germany, Ireland, Italy, Japan, Sweden and the US. We will refer to this as Panel 1. Panel 2 begins in 1972 and adds the Netherlands, Norway, and Spain. Panel 3 begins in 1976 and expands to include Canada, France, and Portugal. Panel 4 begins in 1984 and adds Belgium, Denmark, Greece,

\footnotetext{
${ }^{12}$ Many related studies focus on participation rates rather than employment to population ratios. At a broad level this distinction is not first order-Figure 1 would present the basic pattern if we instead reported participation rates. We prefer to focus on employment rather than participation for the simple reason that in many countries the UI system was used as a shadow social security system for older unemployed workers, creating the possibility that the participation rate could be misleading in some countries.

${ }^{13}$ There are a few idiosyncratic issues with the data for which we make some adjustments. The Italian data reveal a break in the early 1980s for the 45-54 and 55-64 groups. We adjust employment to population ratios for these two groups in the pre 1983 period so that values in 1981 are the same as in 1983. Norway does not report data for a few years in the late 1990s and Ireland reports data at five year intervals in the early part of the sample. For Ireland and Norway we fill in the missing years using linear interpolation.
} 
South Korea, and the UK. Panel 5 includes the remaining countries (Austria, New Zealand, Switzerland) and begins in 1994.

For the first part of our analysis we use data from the LIS (Luxembourg Income Study). This data allows us to examine employment to population ratios by age, gender and marital status, which will be relevant for assessing the narrative that changes in the employment patterns of older females are a key factor in the trend reversal for males. While this data set provides coverage for 17 of the countries in our sample, sample sizes vary and are quite small in some cases. Additionally, the data is available at selected years rather than annually, and the sample period differs quite a bit across countries.

We close this section by providing a more thorough presentation of the motivating fact presented in the Introduction in Figure 1. Figure 3 plots the mean employment rate for males aged 55-64 for each of our 5 different balanced panels.

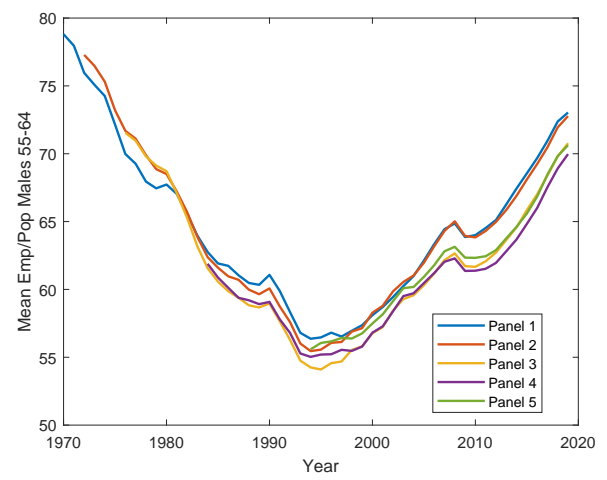

Figure 3: Mean Emp/Pop Rate, Males 55-64 by Panel

While each successive panel considers a shorter time period and a larger sample of countries, all five panels paint a consistent picture over any overlapping 
periods. Specifically, the key pattern that emerges is that the employment rate follows a U-shaped pattern. It declines by a bit more than 20 percentage points between 1970 and the mid 1990s, at which point it reverses direction and begins a steady increase. From the mid 1990s to the end of our sample, 2019, the mean employment to population ratio has increased by about 15 percentage points. The effect of the Great Recession is clearly visible. As of 2019, the employment to population ratio is about 5 percentage points lower than it was in the early 1970 s, about the same as it was in 1976, and higher than it was in 1984.

The magnitude of these changes is striking. The 20 percentage point decline between 1970 and the mid 1990s is as large as the much studied increase in female employment rates over the period 1970-1990. While the changes are very large, a simple calculation provides useful perspective on the magnitudes. Consider a representative worker that is choosing a retirement date. If the worker retires at age 65 then the employment rate for males aged 55-64 will be 100 percent. Moving retirement up by 1 year will lead to a decrease of this ratio by 10 percentage points, so a 20 percentage point drop in the employment to population ratio for this group is equivalent to individuals choosing to retire two years earlier. Over a 25 year period this would be achieved if each successive cohort retires one month sooner than its immediate predecessor.

If we view these changes from a lifetime perspective and consider for concreteness an individual that begins working at age 20, then a two year change in retirement age amounts to a less than five percent change in lifetime labor supply, so that each successive cohort is simply reducing lifetime labor supply by 0.2 
percent. The key message here is that relatively small changes in lifetime labor supply can manifest themselves as extremely large changes in labor supply for a given age group if the change in labor supply is achieved through changes in retirement age.

\section{Employment of Older Females: Driving Force or Part of the Puzzle?}

In this section we examine the narrative offered by Schirle (2008). As noted in the introduction, a key element of this narrative is that non-market work times of spouses are complements, so that holding all else constant, an exogenous increase in the employment rate for older women would decrease the value of leisure for older males, thereby creating a force for later retirement. As Schirle (2008) notes, because higher female employment also gives rise to an income effect, thereby generating an opposing force on male retirement, the complementarities between non-market times of spouses must be sufficiently strong to dominate the income effect. In the appendix we carry out a simple exercise to explore the interaction of these two effects and the extent of complementarity that is needed to overcome the income effect. We also highlight that if the increase in female employment is accompanied by an increase in relative wages of females, it requires significantly more complementarity to overcome the income effects.

A first pass at assessing this narrative is shown in Figure 4, which shows the employment rates for both males and females aged 55-64 for the same set of 14 countries as in Figure 1.

The striking feature revealed by this figure is that the trend break in the employment rate series for older males occurs at virtually the same time as a 


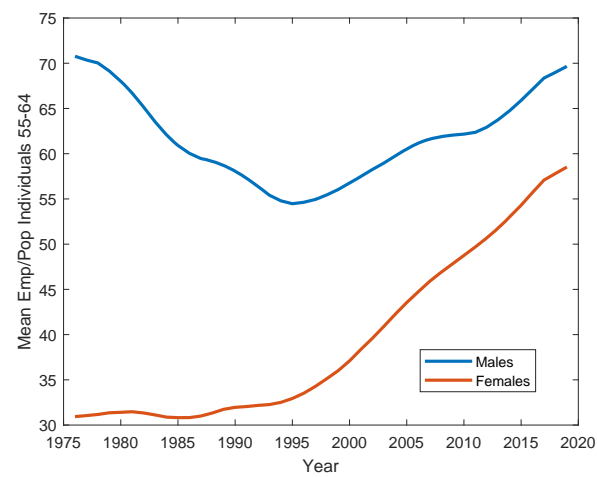

Figure 4: Mean Emp/Pop Rate for Ages 55-64 by Gender

trend break in the employment rate series for older females, thus lending support to the above narrative.

While Figure 4 is consistent with the Schirle narrative, it is also consistent with an alternative narrative in which employment rates of both males and females are responding to some common factor. To address this concern, the other key element of the Schirle narrative is an argument for why the increase in employment rates for older females in the 1990s can plausibly be viewed as exogenous with regard to forces at work in the 1990s. In particular, it posits that beginning in the 1960s, young women entered the labor market with different expectations regarding careers, leading to very significant cohort effects for female employment rates by age. Because the cohort of women that turned 20 in 1960 would turn 55 in 1995, it would be around this time that males aged 55-64 would be increasingly likely to be married to a female who was engaged in market work.

In spite of the encouraging pattern reflected in Figure 4, here we argue that the Schirle narrative is unlikely to be the dominant factor behind the trend reversal 
for males. Two facts support this position. First, examining micro data for a large set of countries, we show that the timing and magnitude of the trend reversal is effectively the same for males that live alone as it is for males that are married or living with a partner. This suggests that leisure complementarities are unlikely to be a dominant factor in explaining the trend reversal. ${ }^{14}$

Second, we argue that the timing of this narrative does not account for the time profile for females shown in Figure 4. Using the lagged employment rate of females aged 45-54 as a way to control for cohort effects in the employment rate of females aged 55-64, we conclude that the sharp increase in employment rates for females aged 55-64 should have begun at least ten years earlier. That is, the period prior to the mid 1990s is a period in which employment of older females is depressed relative to trend. Put somewhat differently, whereas the Schirle narrative proposes that female employment patterns are the solution to the puzzle, our analysis suggests that they are instead just another piece of a larger puzzle. Importantly, the narrative that we develop next does not stress gender specific factors and so can account for why patterns are similar for both older males and older females.

\subsection{Employment Rates and Living Arrangements}

The publicly available OECD data does not allow us to break down employment to population ratios by age, gender and living arrangements (i.e., living

\footnotetext{
${ }^{14}$ While we use the term leisure complementarities, the actual economic mechanism relies on complementarities between time not spent in market work, and so, for example, does not distinguish between leisure time versus home production time. Rogerson and Wallenius (2019) examine changes in time use for couples at retirement and estimate that leisure times are substitutes not complements.
} 
alone versus married or living with a partner). For this reason we turn to data from the LIS (Luxembourg Income Study), which does allow us to examine the data at this level of disaggregation. As noted earlier, two drawbacks of this data set are that the coverage is less than annual and the sample sizes are somewhat small for some countries.

In the interests of space, here we present figures showing the evolution for six countries: the three countries that Schirle (2008) originally studied (Canada, the UK and the US) and three countries that experienced particularly large swings in male employment (Finland, Germany, and the Netherlands). Results are shown in Figure 5.
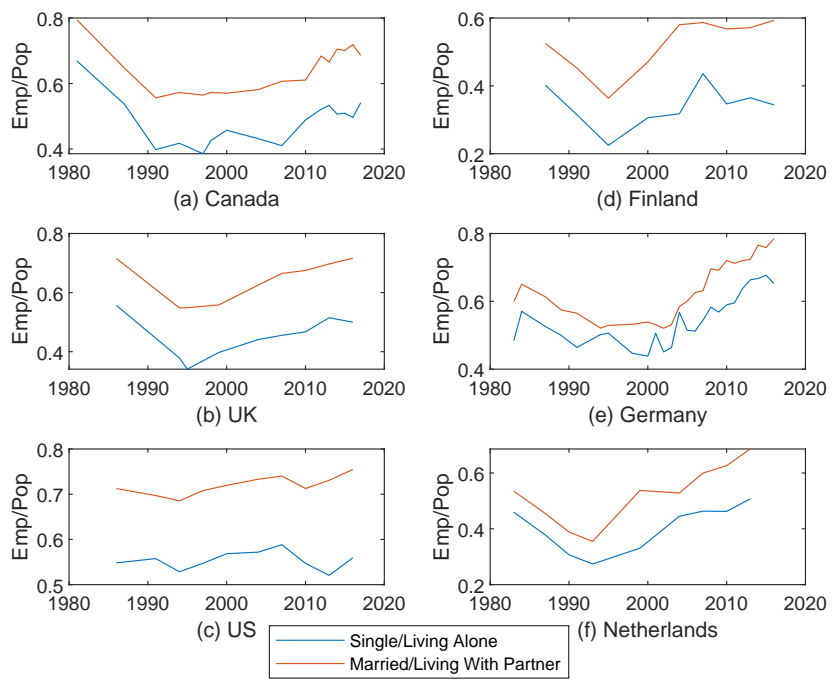

Figure 5: Emp/Pop Rate for Males 55-64 by Living Arrangements

The message from all six of these plots is the same: although there are level differences between the employment rates of males aged 55-64 with different living 
arrangements, the timing and magnitude of trend reversals are very similar across the two groups. While this does not imply that leisure time complementarities do not play any role, it does cast doubt on them being the dominant factor behind the trend reversal. ${ }^{15}$

\subsection{Timing of Employment Changes for Older Females}

While the data just presented already cast doubt on the narrative that stresses higher female employment as the key driving force, it is instructive to consider another element of this narrative, namely the timing of the increase in the employment rate for older females. As previously shown in Figure 4, there is a sharp increase in the trend growth of the employment rate for older females in the mid 1990s. A key element of the Schirle narrative is that this change in trend growth rates is the result of changes in female labor supply choices originating several decades previously, that in turn create ripple effects as the successive cohorts age.

This logic suggests that the growth in employment rates for females aged 45-54 between year $t-10$ and year $t-1$ should be a good proxy for the "exogenous" component of the growth in employment rates for females aged 55-64 between year $t$ and year $t+9$. In what follows we examine this relationship both averaged across countries as well as in each of several individual countries.

We start by presenting results based on cross-country averages. Because this exercise involves lags, we implicitly lose the first ten years of data, making it useful to have the longest panel possible. For this reason we carry out this exercise using

\footnotetext{
${ }^{15}$ We emphasize that this mechanism not being the dominant force behind the trend reversal is fully consistent with the possibility that it exerts some positive effect on male employment rates, just as is true for both improving health and increasing educational attainment.
} 
Panel 1, which starts in 1970 and consists of 6 countries. Figure 6 displays the results, where both series are normalized to zero in 1980 to focus attention on the relative trends.

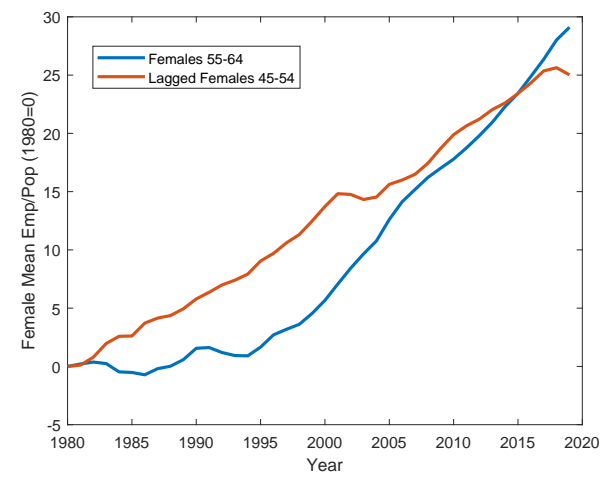

Figure 6: Predicted vs Actual Emp/Pop Rate, Females 55-64

The striking result is that based on this calculation, the employment rate of older females "should" have been growing steadily throughout the entire decade of the 1980s, but in fact was effectively flat up until the mid 1990s. Put somewhat differently, the gap between the actual employment rate for females aged 55-64 and its predicted value based on cohort effect dynamics grew increasingly larger during the entire period from 1980 through to the mid 1990s.

Next we examine the dynamics for six individual countries: Australia, Finland, France, Italy, Sweden, and the US. Results are displayed in Figure 7. In these figures we plot the gap between the two curves that were displayed in Figure 6, with a negative value indicating that the actual employment rate for females aged 55-64 lies below what would have been predicted based on lagged growth in the employment rate of females aged 45-54. Initial values are normalized to zero. 

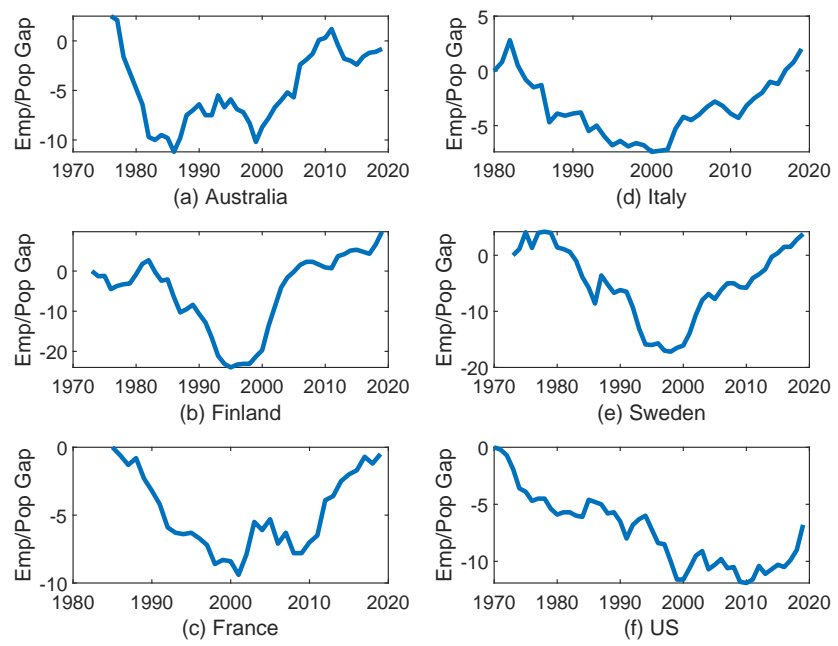

Figure 7: Gap in Actual vs Predicted Emp/Pop, Females 55-64

There are some differences across countries, but in each of these six cases we see the U-shaped dynamics that we saw in the plots for the employment rates of males aged 55-64. In several cases the terminal value is close to zero, implying that by 2019 the overall change in the employment rate for females aged 55-64 is very close to what one would predict based on the lagged growth in the employment rate for females aged 45-54. Of course, there is no need for these to be the same, as there may well be changes in an economy that differentially impact the two groups. ${ }^{16}$ Interestingly, the timing of the troughs for these plots is in many cases quite similar to the timing of the troughs for males.

The key message that we take away from this exercise is that once we control for cohort effects, the mid 1990s are a turning point not only for the employ-

\footnotetext{
${ }^{16}$ In fact, a prominent example of this is that several countries increased the normal retirement age for women so that it would coincide with the normal retirement age for men.
} 
ment behavior of males aged 55-64 but also for females aged 55-64. Rather than providing an answer to the puzzle regarding the trend reversal for older male employment rates, a closer examination of employment rate dynamics for older females leads us to conclude that they are actually just another piece of the same puzzle. The narrative that we describe in the next section will shed light on the common dynamics for older male and female workers.

\section{A New Narrative: Shocks and Institutions Version 2.0}

This section presents evidence to support the narrative outlined in the introduction. We proceed in three steps. In the first subsection we document the following fact:

Fact 1: Countries that display a larger decline in the employment rate of older males prior to the mid 1990s also display a larger increase in the period after the 1990s.

The significance of this fact is that it establishes an intimate relationship between the changes prior to the mid 1990s and those subsequent to the mid 1990s. This is important for two reasons. First, if the changes since the mid 1990s were due to the appearance of a new trend factor, it would be an unlikely coincidence that the effect of this new factor across countries would be strongly correlated with the changes associated with the distinct set of factors at play prior to the mid 1990s. Second, to the extent that changes pre and post the mid 1990s are intimately related, it suggests that analyses should jointly consider changes over the two periods.

In the second subsection we document the following two facts: 
Fact 2: The trend change for the employment rate of older males that occurs in the mid 1990s is not unique to older males. For each of the age groups 15-24, 25-34, 35-44 and 45-54, the mean employment rate across countries also displays a trend change in the mid 1990s. In particular, for each of these groups the secular pattern is a decline until the mid 1990s followed by a modest recovery which is eventually interrupted by the Great Recession.

Fact 3: Countries with the largest decrease in the employment rate for prime aged males (35-44) prior to the mid 1990s also have the largest decrease in the employment rate for older males.

These two facts are significant because they suggest a need to analyze employment changes for older individuals in the context of broader changes affecting all age groups. In particular, the decline in the employment rate of older males in the 1970s and 1980s should not simply be assumed to reflect the continuation of the processes that had been operating prior to the 1970s.

In the process of documenting the above facts we will also establish that the magnitude of the low frequency movements in the employment rate of males aged 55-64 is much greater than for prime aged males. In particular, while the overall change between 1976 and 2019 is quite similar across age groups, the depth of the U-shape is much more pronounced for older males.

The third subsection documents the following fact:

Fact 4: The drop in the employment rate of males aged 55-64 relative to the drop in the employment rate of males aged 45-54 between the mid 1970s and the mid 1990s varies significantly across countries. 
Loosely speaking, the countries with the largest declines in the employment rate of males aged 55-64 seem to exhibit "excess" volatility in this employment rate series. This leads us to highlight the role of institutional responses as a reaction to the overall worsening of aggregate labor market conditions. We briefly summarize the set of institutional responses for a sample of countries.

Taken together these facts highlight the important role of the three features of our analysis: contrasting outcomes across countries, focusing on a relatively long time period (at least back to the early to mid 1970s), and considering employment changes for older individuals in the context of overall employment changes.

\subsection{Mean Reversion}

For the results presented here we focus on the sample of countries represented by Panel 3, which consists of 14 countries and starts in 1976. Table 1 reports the year in which the minimum value of the employment rate for males aged 55-64 occurs, the absolute value of the change from 1976 to the year of the minimum, and the absolute value of the change from the year of the minimum to 2019. 
Table 1

Timing and Magnitude of Trend Reversals in Emp/Pop Rate for Males 55-64

\begin{tabular}{cccccccc}
\hline \hline & $t_{\min }$ & $\left|\Delta_{1976, t_{\min }}\right|$ & $\left|\Delta_{2019, t_{\min }}\right|$ & & $t_{\text {min }}$ & $\left|\Delta_{1976, t_{\text {min }}}\right|$ & $\left|\Delta_{2019, t_{\text {min }}}\right|$ \\
\hline \hline AUS & 1993 & 22.4 & 18.2 & JAP & 2002 & 5.8 & 10.0 \\
CAN & 1995 & 19.6 & 15.1 & NET & 1993 & 28.7 & 37.8 \\
FIN & 1995 & 21.5 & 29.9 & NOR & 1991 & 12.8 & 7.9 \\
FRA & 1998 & 28.7 & 21.6 & POR & 2012 & 26.0 & 14.9 \\
GER & 2000 & 18.3 & 30.7 & SPA & 1995 & 29.4 & 12.7 \\
IRE & 2012 & 20.1 & 15.5 & SWE & 1994 & 15.8 & 15.5 \\
ITA & 2001 & 14.3 & 24.2 & US & 1994 & 8.6 & 7.2 \\
\hline
\end{tabular}

The large declines in the years after 1976 are largely transitory (the mean decrease prior to the minimum is equal to 19.4 percentage points, while the mean increase following the minimum is equal to 18.7 percentage points) and the decreases prior to the minimum value being reached are highly correlated with the subsequent increases; the correlation between the decline and increase on either side of the minimum is $.48 .{ }^{17}$ Figure 8 presents a scatter plot of the absolute value of the decreases and increases for the 14 countries in Panel 3, plus a linear regression line.

\subsection{Negative Labor Market Shocks in the 1970s and 1980s}

An important diagnostic in the effort to understand the striking changes in the

\footnotetext{
${ }^{17}$ If we remove Portugal and Spain the correlation increases to 0.69. Because Spain and Portugal are the two poorest countries in the sample in 1976 one might expect them to experience the largest overall decline in employment of older males, and in fact this is the case. If we use Panel 1 and repeat the analysis the correlation is 0.77 .
} 


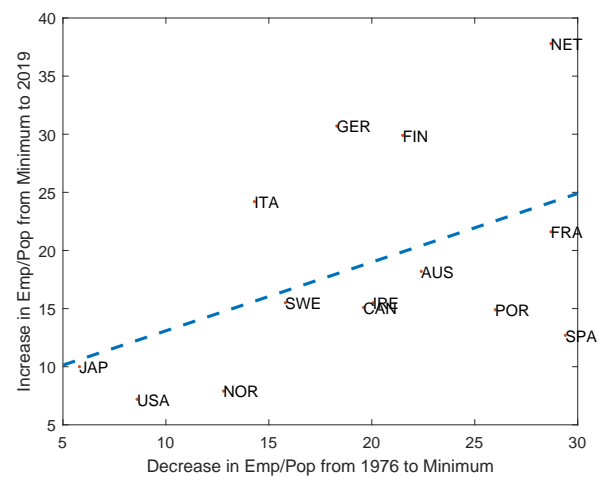

Figure 8: Mean Reversion in Emp/Pop Rate, Males 55-64

employment rate for males aged 55-64 is its behavior relative to other age groups. With this in mind, Figure 9 has four panels that are analogous to Figure 3 but for four other age groups: 15-24, 25-34, 35-44 and 45-54.
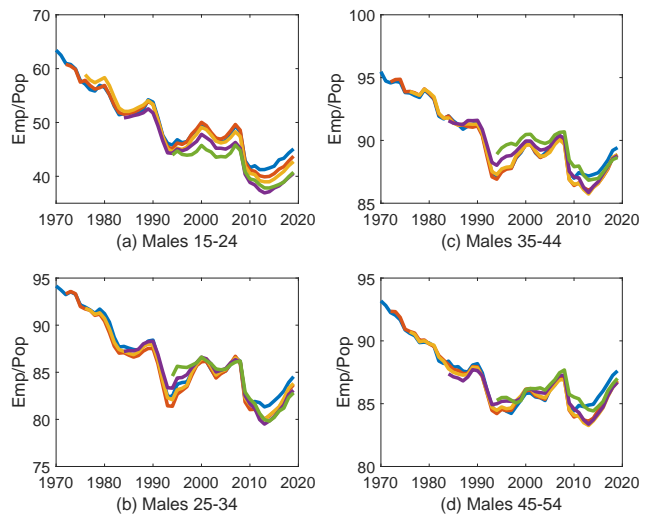

Figure 9: Mean Male Emp/Pop Rate by Age Group

Each of the panels in Figure 9 has its own scale in order to best illustrate the invariance of the key patterns across our samples. For purposes of comparing the results across age groups it is useful to present results for all of the age groups in 
a single figure, which is done in Figure 10 for the countries in Panel 2.

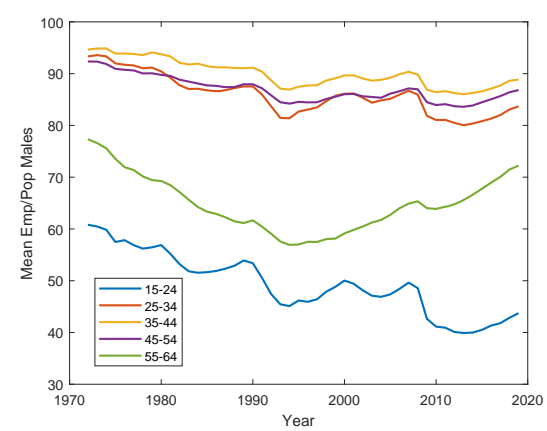

Figure 10: Mean Emp/Pop Rate for Males by Age

We highlight three features of this figure. First, for all age groups, mean male employment to population ratios decrease significantly from 1970 to the mid 1990s. Second, subsequent to the mid 1990s, there is a modest recovery for all age groups other than those aged 15-24, though this recovery is disrupted by the Great Recession. ${ }^{18}$ (For those aged 15-24 the employment rate stabilizes in the mid 1990s but there is no evidence of a subsequent recovery.) Third, both the decline and subsequent recovery for males aged 55-64 are much larger than for any of the prime aged groups.

To highlight the connection between the changes in employment to population ratios across age groups, we compute the correlation coefficient between the declines in the employment rates for prime age (35-44) and older (55-64) males between 1976 and 1995, using the 14 countries in Panel 3. The two are highly positively correlated with a correlation coefficient of 0.69 .

\footnotetext{
${ }^{18} \mathrm{An}$ interesting feature of this figure is that, in contrast to most recessions, the Great Recession seems to have had relatively smaller impacts on older individuals than prime aged individuals. This is not something we pursue here.
} 


\subsection{The Role of Changing Institutions}

Given the evidence presented thus far, our narrative might appear to be nothing more than a minor extension of the earlier shocks and institutions in which we explicitly note the impact on older individuals. That is, a common shock (or series of shocks) had adverse effects on overall labor market outcomes in all economies, but the effects differed across economies, plausibly because of preexisting differences in institutions. The earlier literature did not emphasize how the effects within an economy might vary across age groups, but if one makes the additional plausible assumption that older individuals are more vulnerable to the types of shocks being experienced, then this would also account for the qualitatively different evolutions across age groups.

While this narrative gets one quite far, in this subsection we first argue that an additional factor that directly affects older individuals differentially across countries seems likely to help account for the observed patterns. We then argue that this additional factor is plausibly related to differential institutional changes across countries that directly impact older workers by documenting specific institutional changes in a handful of countries.

We begin by contrasting the relative employment rate dynamics across age groups for two subsamples of Panel 2. Subsample 1 (S1) consists of Australia, Canada, Ireland, Japan, Norway and the US. Subsample 2 (S2) consists of Finland, France, Germany, Italy and Sweden. ${ }^{19}$ For now we simply note that this

\footnotetext{
${ }^{19}$ The Netherlands is excluded because it has missing data for the younger age groups. We exclude Portugal and Spain because they are the poorest countries in our overall sample in 1976 and so are not as easily classified.
} 
partition is consistent with our reading of the literature that documents the extent of institutional changes in the period leading up to the mid 1990s. Figure 11 displays two curves for each subsample: the employment rate for males aged 45-54 and the employment rate for males aged 55-64.

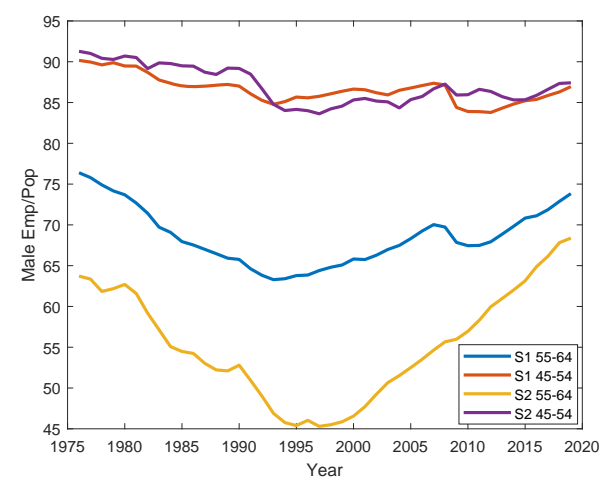

Figure 11: Emp/Pop for Males in Two Subsamples by Age

Several properties of this figure are notable. First, note that for each subsample, the turning point for males aged 45-54 lines up closely with the turning point for males aged 55-64, though the turning points differ across the two subsamples by about 5 years. Second, although employment rates in 1976 are very similar for males aged 45-54 across the two subsamples, these rates are already quite different across the two subsamples for males aged 55-64. Third, although movements in the employment rate for males aged 45-54 are quantitatively quite similar across subsamples, the magnitude of movements in the employment rates for males aged 55-64 are dramatically larger in Subsample 2.

It is the third property that we focus on in this subsection. An alternative way to summarize this property is to say that the elasticity of the employment rate 
for males aged 55-64 with respect to the employment rate for males aged 45-54 is much larger in Subsample 2 than it is in Subsample 1. One possibility is that this differential elasticity is explained by differences in institutions that already existed in 1970. While there is reason to believe that this plays some role, another possibility is that the countries in Sample 2 initiated reforms in response to the shock that served to amplify its effect on males aged 55-64. Note that for this second possibility to be quantitatively important it should be the case that there were institutional changes after the mid 1990s that served to offset the effects of earlier institutional changes, a point we will document later on for a sample of countries.

As another perspective on this issue we examine the evolution of the crosssectional dispersion of employment to population ratios. Figure 12 plots the time series evolution of the standard deviation of the log of employment to population ratios in the cross-section of countries for Panel 3. To highlight the distinctive dynamics for the 55-64 age group we also plot the same statistic for the other age groups.

The most striking feature of this figure is that the substantial variation in the extent of the decline following 1976 leads to a dramatic increase of cross-sectional dispersion in the employment to population ratio for older males across countries, and that the subsequent increase following the mid 1990s leads to roughly an equal decrease, so that dispersion changes relatively little between 1976 and 2019.

While the changes in cross-sectional dispersion for the oldest age group are the single most striking feature of this figure, it is important to note that a similar 


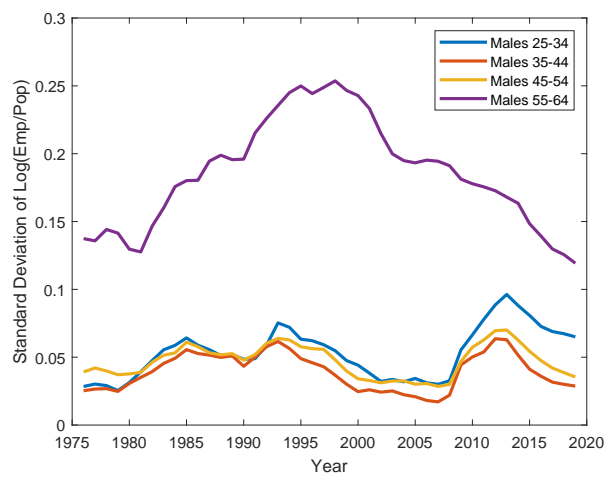

Figure 12: Standard Deviation of Log Male Emp/Pop Rate by Age

hump shaped pattern is found for each of the other three age groups prior to the Great Recession. This is consistent with the earlier shocks and institutions literature that emphasized heterogeneity in responses at an aggregate level. ${ }^{20}$ But importantly, the heterogeneity in responses for older individuals is much larger than the heterogeneity for other age groups.

The idea that institutional change during the 1970s and 1980s specifically targeted at older workers played a key role in the relatively large decline in their employment rate in a large set of countries is not a new one. A large literature has documented the many and varied policies enacted by various governments with the explicit goal of allowing older individuals to get by without working. (For an excellent detailed study of measures adopted in several economies see Kohli et al (1991).)

Importantly, whereas much previous work on the employment of older individ-

\footnotetext{
${ }^{20}$ The significant heterogeneity of labor market consequences during the Great Recession creates a second hump shape beginning in the late 2000s, though this is of less interest for us given our focus on secular changes. It is interesting that this effect does not show up in the series for males aged 55-64.
} 
uals has often focused on permanent features of social security rules, the relevant policy changes in this context are dominated by temporary changes to other programs which are best viewed as having created a shadow social security system. For example, some countries adopted rules that created special programs within the UI system to allow older workers to receive benefits for a longer period of time and create a bridge to the official retirement age. As we describe below, these programs would sometimes create a pathway for an individual to receive UI for as long as ten years starting at age 55. Other countries relaxed rules allowing older individuals to go on disability. Some adopted rules whereby older workers that were laid off would be eligible for early social security if the firm replaced the individual with a younger worker. In some cases these changes took place via a change in the way that state agencies interpreted the policy rules about eligibility and so were not at all reflected in any statutory change in policy. One example is the issue of whether difficulty finding work for an older individual is a valid criterion for receipt of disability.

The diverse nature of the various institutional changes that were implemented makes it challenging to produce meaningful and comparable summary measures that can be used for more formal or rigorous cross-country comparisons. ${ }^{21}$ For this reason we will simply summarize the experiences of a few countries to illustrate some of the rather extraordinary measures that were taken. But before doing so we want to address two other issues. The first concerns motivation for the

\footnotetext{
${ }^{21}$ These challenges notwithstanding, see Borsch-Supan and Coile (2020) for details regarding a procedure for mapping a rich set of institutional characteristics into a single measure that summarizes the implicit tax on continuing to work at older ages.
} 
expansion of the shadow social security systems: why did these countries adopt measures specifically targeting older individuals? The second concerns the timing of the subsequent contraction of these shadow social security programs: if the trend reversal in employment rates for males aged 55-64 is at least in part due to the gradual reduction in these measures targeted at older individuals, then why was the timing of these reforms so similar across countries?

Regarding the first issue, we highlight two points. First, older workers generally fare much worse following displacement than do younger workers. Research has shown that older workers subjected to layoffs experience both longer duration of unemployment spells and larger wage losses upon reemployment. (See, e.g., Farber (1997).) It follows that these workers will plausibly be the most affected by the type of economic restructuring that took place in response to the shocks of the 1970s and 1980s. Whether due to their concerns for overall wellbeing or political pressure brought by groups representing older workers, this reality might naturally lead policy makers to take special steps to shield older workers from the effects of diminished labor market opportunities.

Second, amid the broad deterioration in overall labor market opportunities, policy makers in several countries subscribed to the so called "lump of labor" fallacy which held that there were a fixed number of jobs available, so that creating an employment opportunity for one individual required removing another individual from employment. In some European economies that were experiencing sharp increases in unemployment among young people, policy makers thought that encouraging older workers to leave the labor force would serve to create op- 
portunities for younger individuals. Importantly, this rationalization implied that policy might actively encourage older workers in stable employment relationships to leave the labor force.

Why such synchronicity in the reversal of these reforms? Here we note three factors that we think are relevant. First and most important were the fiscal consequences of the accumulated reforms. The fiscal burden associated with supporting so many individuals out of work led to large budget deficits, especially in those countries with the most aggressive policy changes. These fiscal pressures would naturally be highly correlated across economies. Moreover, the planned adoption of the Euro was associated with pressures for fiscal reform and so necessarily created a desire for fiscal reform that was correlated across many of the economies in our sample. Second, and related, several European economies experienced severe contractions in overall economic activity in the early to mid 1990s and came to feel that broad based reforms were necessary. And third, policy makers came to realize the fallacy of the "lump of labor" perspective, therefore removing some of the initial rationale for the reforms that had been adopted. ${ }^{22}$

In the remainder of this subsection we briefly summarize the institutional changes adopted in a few countries as a way to illustrate the types of changes that occurred. Specifically, we will highlight changes in Finland, France, Germany and the Netherlands.

\section{Finland}

\footnotetext{
${ }^{22}$ The OECD Jobs Report was also released in the early 1990s, and this also represented somewhat of a turning point in terms of overall approaches to labor market regulation and job creation.
} 
Finland is a striking example of how the UI system can be used to create a shadow social security system. ${ }^{23}$ This system is known as the "unemployment tunnel" and consists of a few distinct programs that can be pieced together sequentially.

One piece is the unemployment pension. Beginning in the early 1970s, longterm unemployed individuals over the age of 60 became eligible for unemployment pension after collecting earnings-related unemployment benefits for 200 working days. The eligibility age was lowered to 58 in 1978 and lowered again to 55 in $1980 .^{24}$

A second piece is extended benefits. In 1991, older individuals became entitled to earnings-related unemployment benefits until reaching the eligibility age for unemployment pension, provided they had reached the age of 55 by the time the normal unemployment benefit should have ended. Since the maximum duration for unemployment benefit collection for other age groups is roughly 2 years, this policy meant that individuals could potentially collect earnings-related unemployment benefits from age 53 until the official retirement age. This would be achieved by a combination of three separate UI programs: the regular program from age 53-55, the extended benefits program for older individuals from age 55-60, and the unemployment pension from age 60 to 65 . It is this sequence of programs that is referred to as the unemployment tunnel.

One additional change was also implemented in the early 1990s. Prior to the

\footnotetext{
${ }^{23}$ See Hytti (2004) for additional details beyond the summary provided here.

${ }^{24}$ During 1986-1990, the minimum age was gradually raised back to 60 , but as we note below, this was rendered irrelevant by the extension of other programs in the early 1990s.
} 
1990s, older individuals (i.e., individuals aged 57) could collect unemployment benefits for a maximum of 900 working days. But few individuals hit this maximum in practice, as under legislation introduced in 1987, older individuals were entitled to subsidized employment after a one-year unemployment spell. But during the 1990s recession, the requirement to provide subsidized employment was lifted.

Starting in the mid 1990s Finland undertook a series of reforms to weaken the unemployment tunnel. In 1997, the eligibility age for the extended benefit entitlement period was increased from 53 to 55 . Around the same time, the generosity of the unemployment pension benefits was reduced. A number of additional reforms to old-age retirement were implemented in 2005. These included a flexible retirement age with substantial deductions for early claiming, as well as basing the old-age retirement benefit on lifetime earnings rather than earnings from the best 10 years.

\section{France}

France is another example of how the UI system was used to initially provide income security for older workers who became displaced. ${ }^{25}$ In 1972 the system was expanded to provide protection for older displaced workers, providing a guaranteed income to dismissed workers age 60 or older. In 1977 the system was expanded to provide access to workers aged 60 and older who quit voluntarily, making it a de facto early retirement scheme. Interestingly, these provisions for UI were actually more costly than the provisions that these workers would have received if they

\footnotetext{
${ }^{25}$ See Guillemard (1991), Bozio (2008) and Charni (2016) for more extensive discussions.
} 
had instead been moved to the official social security system.

In fact, understanding the fiscal reality of the situation, in 1983 the government gave in to long standing pressure from the unions to lower the official retirement age from 65 to 60 , for the simple reason that doing so would actually reduce expenses. Not surprisingly, the lowering of the official retirement age in 1983 had no discernible effect on the employment rate of workers aged 55-64. This is because the pre-existing UI reforms had already created a shadow social security system with a retirement age of 60 . This episode serves as an important reminder of the importance of shadow social security programs and a cautionary tale of the danger of not accounting for the features of the shadow social security programs when evaluating the effect of changes in features of the formal social security program.

There have been a series of reforms in France in the 1990s and 2000s, starting with 1993. The number of years used to compute the retirement benefit was increased from the best 10 to the best 25 years. Required contributions were raised from 37.5 to 40 years, and later further to 41 years. The reforms in the 2000s also introduced increased benefits for delayed retirement and raised both the minimum and full retirement ages by 2 years.

Because the 1983 changes effectively codified the expansion of the shadow social security system into the formal social security system, the subsequent contractions have largely occurred within the formal social security system.

Germany

Germany provides an excellent example of the complexity of the features and 
circumstances that combine to define the shadow social security system. First, it illustrates the importance of both institutional features in place prior to the 1970s as well as changes that occurred over time in response to changing labor market outcomes. Second, it shows that some changes were purposeful actions taken by policy makers while others became effective because of court decisions challenging the interpretation of statutes. Third, it illustrates the use of multiple pathways: the disability system and the UI system. Additionally, the reforms in Germany since 1990 are clear evidence about policy actions taken to contract the shadow social security system, though several of these reflect changes in the formal social security system. A brief overview of these changes follows. ${ }^{26}$

Prior to 1970 the German social security system stipulated that 65 was the normal retirement age. However, dating back to 1957, the system had a stipulation that allowed an individual to collect a pension at age 60 if they had experienced at least 52 weeks of unemployment during the previous one and a half years. While this provision had little impact prior to the 1970s, it would become an important element of the early retirement pathway when labor market prospects deteriorated. In 1973 the system was revised to allow for early retirement at age 63 with no actuarial reduction in benefits. In 1976 a court ruling stipulated that inability to find suitable employment became a criterion for receiving disability. Between 1978 and 1980 the eligibility age for old age handicapped pensions was reduced from 62 to 60 .

The late 1980s witnessed a series of expansions in the duration of UI benefits

\footnotetext{
${ }^{26}$ See the discussions in Jacobs et al (1991) and Benita (2009) for more details.
} 
for older individuals. In 1985 the maximum duration was increased from 12 to 18 months for those aged 49 and older. In 1986 the duration was increased to 20 months for those aged 49-53 and to 24 months for those age 54 and older. In 1987 the duration was extended to 32 months for those 54 and older. Additional changes in the mid 1980s created financial incentives for firms to lay off workers aged 58 and older if they replaced them with a currently unemployed individual.

The German retirement system has subsequently been scaled back through a series of reforms, starting in 1992, reflecting changes in both the shadow social security system as well as the formal social security system. The 1992 reform introduced a gradual change of eligibility ages for pensions for women and unemployed individuals from age 60 to age 65 and for disability pensions from age 60 to 63. Actuarial adjustments, with age 65 as the benchmark, were also implemented as part of the reform. (Prior to 1992, adjustment of benefits based on the age at retirement were only implicit via the number of years of contributions.) Another major change was the indexing of benefits to net rather than gross wages. Subsequent reforms in the 2000s have heralded a shift away from the monolithic system to a multi-pillar system with supplementary occupational and private pensions. The 2007 reform also increased the statutory retirement age from 65 to 67 .

\section{Netherlands}

Generous early retirement plans were introduced in the mid 1970s with the explicit goal of replacing old workers with young ones. ${ }^{27}$ There were two widely utilized pathways into early retirement, a pay-as-you-go early retirement pro-

\footnotetext{
${ }^{27}$ See de Vroom and Blosma (1991) and Visser et al (2016) for a more extensive summary.
} 
gramme VUT ('Vervroegde UitTreding') and a disability scheme WAO ('Wet ArbeidsOngeschiktheid'). The early exit options were very generous, with replacement rates of up to $80 \%$ already at age 55 .

A series of reforms in the 1990s and 2000s have curtailed disability insurance. In 1992, insurance premiums of employers with increased disability incidence were raised. In 1993, disability benefits became dependent on earnings histories, which lowered replacement rates for workers who went on disability at younger ages. Stricter medical eligibility criteria and more intensive follow-ups for disability benefit recipients were introduced in 2002. A new program was introduced in 2006 with the goal of distinguishing between fully/permanently disabled and partially/temporarily disabled individuals. The program aimed at getting disabled workers back to work.

During the same time period, the early retirement program VUT has also been scaled back. In 1997 the program was replaced by less generous pre-pension arrangements with penalties for early benefit claiming. A further law change in 2006 eliminated fiscal advantages of early retirement schemes and made them more actuarially fair.

\section{Patterns for Males Aged 65-69}

Our analysis has thus far focused on the dynamics in the employment rate for males aged 55-64. In doing so we found it useful to examine the dynamics for this

group in the broader context of the employment rate dynamics experienced by males from younger age groups. It is similarly of interest to examine the behavior of males in an older age group, and so in this section we examine the employment 
rate dynamics of males aged 65-69. One limiting issue is that the OECD data is more limited for this particular age group. For this reason our analysis will focus on a somewhat smaller set of countries and a somewhat shorter time period.

We begin by presenting the dynamics for the employment rate of males aged 65-69 for the six countries that have data available prior to 1980: Australia, Canada, France, Norway, Sweden and the US. As before, we plot five year moving averages in order to better highlight the secular trends. Results are shown in Figure 13.

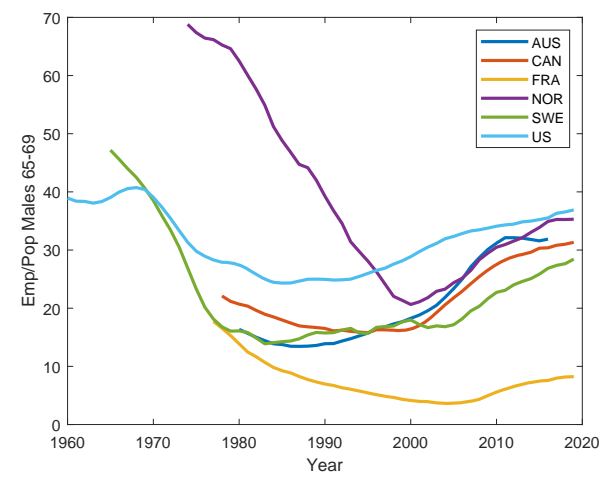

Figure 13: Emp/Pop Rate, Males 65-69

Three features stand out. First, for each country this age group exhibits the same U-shaped dynamics that we observed for other age groups. Second, in most cases the bottom of the $\mathrm{U}$ tends to be quite flat, so that although the decline effectively ceases as early as the mid 1980s for several countries, the sharp increases mostly occur in the 2000s. Third, for the four countries with the earliest starting dates for data (France, Norway, Sweden and the US), the terminal employment 
rate remains below its value from the early 1970s. For Canada and Australia the terminal employment rate exceeds its initial value, but it is likely that this is an artifact of the earlier data being censored. ${ }^{28}$

Figure 13 suggests that the 2000s are of particular interest for studying the increase in the employment rate for males aged 65-69. Because we also have a full balanced panel for this age group starting in 2002, we will focus on this time period in what follows. Figure 14 shows the behavior of the sample means for the employment rates of both the 55-64 and 65-69 age groups.

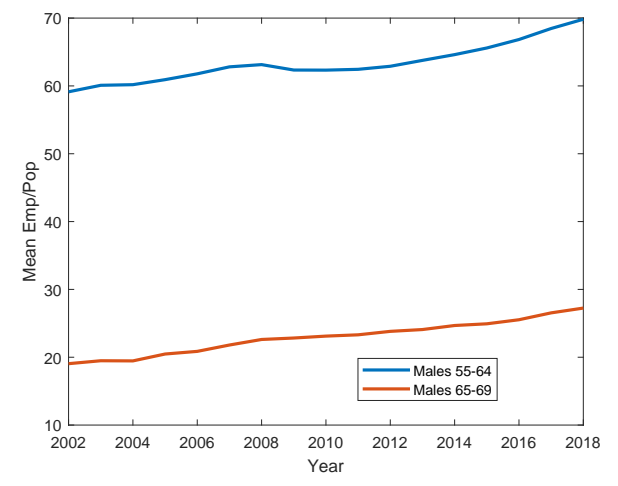

Figure 14: Mean Emp/Pop Rate for Older Males

Both curves display a steady upward trend. The increase for the group aged 55-64 is about 11 percentage points, while the corresponding increase for the group aged $65-69$ is about 8 percentage points. In comparing these numbers it is useful to be mindful of the fact that the age intervals are of different length; a given percentage point increase in the employment rate for each of the two groups

\footnotetext{
${ }^{28}$ The series for Norway is interesting in its own right. Delving into the specifics is beyond the scope of our analysis here, but we note that whereas most countries had a normal retirement age of 65 at the beginning part of our sample, Norway had a normal retirement age of 67 .
} 
corresponds to an increase in person-years of employment that is twice as large for the $55-64$ group. $^{29}$

Next we focus on the cross-sectional relationship between the changes in the two employment rates. Figure 15 displays a scatter plot, where each point represents one of the countries in our sample.

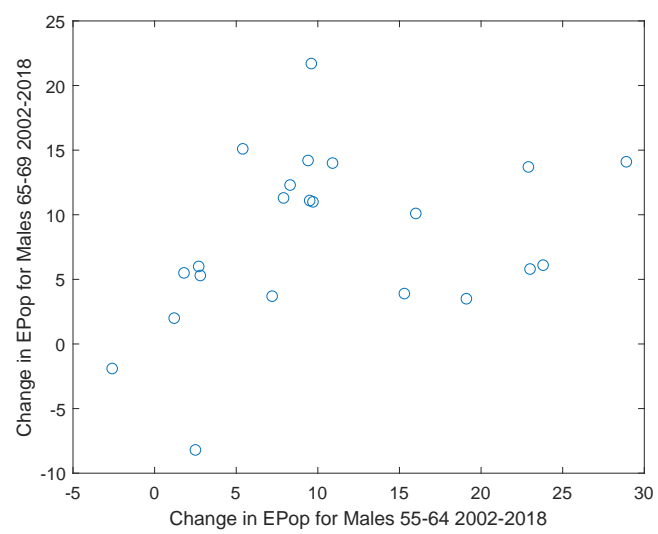

Figure 15: Changes in Male Emp/Pop Rates for Older Males: Full Sample

Two features stand out. First, there is a positive correlation between the two changes, with the correlation coefficient being .33. But second, the relationship seems to exhibit a sharp non-linearity: if we focus on the countries for which the employment rate for males aged 55-64 increased by less than fifteen percentage points we see a very tight positive relationship, whereas for those countries with an increase in the employment rate for males aged 55-64 of more than fifteen

\footnotetext{
${ }^{29}$ As a different perspective on this, consider an economy with a representative agent. If the representative agent retires in the interval $55-64$ and postpones retirement by one year then the employment rate increases by ten percentage points. But if the representative agent retires in the 65-69 interval and delays retirement by one year the employment rate increases by twenty percentage points.
} 
percentage points there appears to be no relationship.

To highlight this, Figure 16 shows the scatter plot when we restrict attention to those countries that had increases of less than fifteen percentage points.

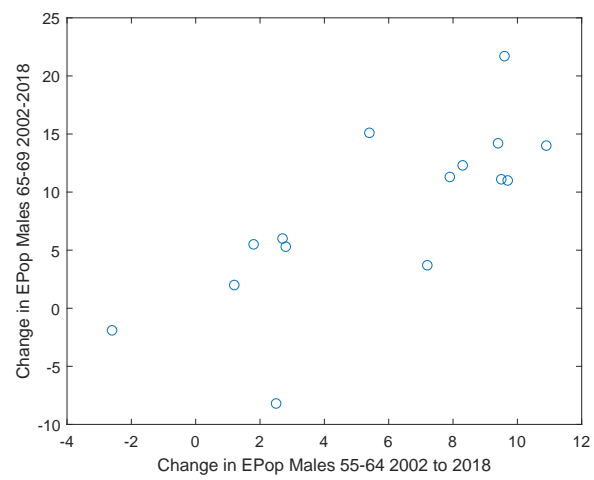

Figure 16: Changes in Male Emp/Pop Rates for Older Males: Restricted Sample

Consistent with the previous discussion, this figure shows a very tight positive relationship, and the correlation coefficient is now 0.76 . The countries that are excluded from this plot are Austria, Belgium, Finland, France, Germany, Italy and the Netherlands. Notably, this list is comprised entirely of Western European countries and includes the four countries that we highlighted in the previous section to exemplify countries that adopted policy changes that served to amplify the response of employment rates for individuals aged 55-64.

To connect this evidence with our earlier narrative, recall that our narrative stresses two factors. First, there is a low frequency and mean reverting negative shock that affects labor markets over the period from the mid 1970s through to the present time. Second, in some but not all countries, superimposed upon this underlying process is a process of institutional reform that first expands and 
later contracts the shadow social security system options available to individuals in the 55-64 age group, thereby amplifying the changes for this group. Because individuals in the 65-69 age range are affected by the true social security system rather than the shadow social security system, it is plausible to assume that they are relatively unaffected by this process of expansion and contraction of the shadow social security system.

Under this assumption, we would expect to see the sort of non-linear relationship pictured in Figure 15. For countries in which the process of institutional reform was relatively modest, the changes in employment rates for males aged 55-64 and 65-69 are largely driven by common factors and hence should be highly correlated ${ }^{30}$ But for those countries in which the process of institutional reform had a large impact on males in the 55-64 age group, this correlation should be much less evident.

\section{Conclusion and Directions for Future Research}

The goal of this paper has been to offer a new narrative for understanding the changes in employment rates of older males as previously displayed in Figure 1. Key to this narrative is that much of the decline between the mid 1970s and the mid 1990s should be understood as the result of negative shocks to aggregate labor markets as well as temporary policy measures that amplified the effects of these shocks on older males. In particular, much of the increase in the post 1995 period should be interpreted as reflecting reversion to the mean as opposed to a new "trend". We also argued that employment rates for older females experienced

\footnotetext{
${ }^{30}$ We note that the set of common factors includes slow moving trends such as health and educational attainment in addition to improving labor market prospects.
} 
similar dynamics relative to trend and that our narrative can also explain why older females experienced similar dynamics.

Our analysis has focused on the broad brush strokes associated with this narrative and so is only a first step toward a deeper understanding of the evolution of employment rates for older males. In this final section we want to highlight what we see as four important next steps.

First, our analysis has relied almost exclusively on aggregate data. An important next step is to document the key changes over time in each country at a disaggregated level using micro data. Ideally this would be done using data that allows us to follow individuals over time to better understand the patterns of withdrawal from employment.

Second, more work needs to be done to generate comprehensive information on the family of institutional features that describe the relevant context for older workers across countries. This will be necessary for carrying out more rigorous analyses of the effects of policies on older workers. The contributions in BorschSupan and Coile (2020) is an important step in this direction.

Third, more effort should be directed to documenting and modeling the heterogeneous situations faced by older individuals in the labor market to better understand retirement dynamics. Whereas some individuals leave the workforce on account of having amassed sufficient resources to cover their retirement years, others are leaving despite having amassed few resources but on account of having very poor prospects for paid employment. Relative to younger workers, older workers face both different shocks and different prospects following these shocks. 
Fourth, and related to the previous point, the implications of the changing employment rates for older males need to be studied from a welfare perspective, and in particular, need to be combined with an analysis of wage dynamics. The programs that were expanded during the 1970s and 1980s to help older workers did serve to shield these workers from the effects of adverse shocks. As these programs have contracted, many older individuals find themselves employed but much more susceptible to adverse shocks. Recent studies have begun to document these effects. See, for example Visser et al (2016) for the case of the Netherlands and Buchholz et al (2013) for the case of Germany. 


\section{References}

Blanchard, O., and J. Wolfers. 2000. "The Role of Shocks and Institutions in the Rise of European Unemployment: The Aggregate Evidence", Economic Journal $110,1-33$.

Borsch-Supan, A. and C. Coile. 2019. Social Security Programs and Retirement Around the World: Reforms and Retirement Incentives. University of Chicago Press, Chicago, USA.

Bozio, A. 2008. "Impact Evaluation of the 1993 French Pension Reform on Retirement Age." Pensions: An International Journal 13, 207-212.

Bruno, M. and J. Sachs. 1985. Economics of Worldwide Stagflation. Harvard University Press, Cambridge, USA.

Buchholz, S., A. Rinklake, and H. Blossfeld. 2013. "Reversing Early Retirement in Germany." Comparative Population Studies 38, 881-906.

Burtless, G. 2013. "Can Educational Attainment Explain the Rise in Labor Force Participation at Older Ages?" Center for Retirement Research at Boston College. Charni, K. 2016. "French Pension Reforms and Their Impact on Older Unemployed Workers." Working Paper, Aix-Marseille University.

Clark, K. and L. Summers, 1981. "Demographic Differences in Cyclical Employment Variation." Journal of Human Resources 16, 61-79.

Coile, C., K. Milligan, and D. Wise. 2019. Social Security Programs and Retirement Around the World: Working Longer. University of Chicago Press, Chicago, USA. 
Costa, D. 1998. The Evolution of Retirement: An American History, 1880-1980. University of Chicago Press, Chicago, USA.

Farber, H. 1997. "The Changing Nature of Job Displacement 1881-1995." Brookings Papers on Economic Activity: Microeconomics, 28, 55-142.

Gomme, P., R. Rogerson, P. Rupert and R. Wright. 2004. "The Life Cycle and the Business Cycle." NBER Macroeconomics Annual 19, 415-461.

Greenwood, J., and M. Yorukoglu. 1997. "1974." Carnegie-Rochester Conference Series on Public Policy 46, 49-95.

Guillemard, A. 1991. "Massive Exit Through Unemployment Compensation." in Time for Retirement, Martin Kohli, Martin Rein, Anne-Marie Guillemard and Herman van Gunsteren, editors, Cambridge University Press.

Hornstein, A. and P. Krusell. 1996. "Can Technology Improvements Cause Productivity Slowdowns." NBER Macroeconomics Annual 11, 209-276.

Hytti. 2004. "Early Exit from the Labour Market Through the Unemployment Pathway in Finland." European Societies, 6:3, 265-297.

Jacobs, K., M. Kohli, and M. Rein. 1991. "Germany: The Diversity of Pathways." in Time for Retirement, Martin Kohli, Martin Rein, Anne-Marie Guillemard and Herman van Gunsteren, editors, Cambridge University Press.

Kohli, M., M. Rein, A. Guillemard, and H. van Gunstern.1991. Time for Retirement. Cambridge University Press.

Krugman, P. 1994. "Past and Prospective Causes of High Unemployment." Economic Review, Federal Reserve Bank of Kansas City 79, 23-43. 
Ljungqvist L., and T. Sargent. 1998. "The European Unemployment Dilemma." Journal of Political Economy 106, 514-550.

Luxembourg Income Study (LIS) Database, http://www.lisdatacenter.org (multiple countries; February 3, 2020-June 23, 2020). Luxembourg: LIS.

Mortensen, D. and C. Pissarides. "Unemployment Responses to Skill-Biased Technology Shocks." Economic Journal 109 (1999) 242-265.

Rogerson, R., and J. Wallenius. 2019. "Household Time Use Among Older Couples: Evidence and Implications for Labor Supply Parameters." Quarterly Journal of Economics 134, 1079-1120.

Schirle, 2008. "Why Have Labor Force Participation Rates of Older Men Increased Since the Mid-1990s?" Journal of Labor Economics 26, 549-594.

Vandenbroucke, G., 2009. "Trends in the Hours: The U.S. from 1900 to 1950." Journal of Economic Dynamics and Control 33, 247-249.

Visser, M., M. Gesthuizen, G. Kraaykamp, and M. Wolbers. 2016. "Trends in Labour Force Participation of Older Men: Examining the Influence of Policy Reforms, Normative Change and Deindustrialization in the Netherlands, 19922009." Economic and Industrial Democracy 37, 425-447.

Wilke, Christina. 2009. "German Pension Reform: On Road Towards a Sustainable Multi-Pillar System." Frankfurt Am Main: Peter Lang AG. 


\section{Appendix}

In this appendix we study a simple model of family labor supply in which the non-market times of the two spouses are complements and report the results of some simple exercises. The household has utility from (joint) household consumption $(c)$ and household non-market work time $(l)$ :

$$
\log C+\frac{\alpha}{1-\frac{1}{\gamma}} N^{1-\frac{1}{\gamma}}
$$

where household non-market work time is a CES aggregate of the non-market work time for the male $\left(l_{m}\right)$ and female $\left(l_{f}\right)$ members of the household:

$$
N=\left[a_{m} n_{m}^{\rho}+a_{f} n_{f}^{\rho}\right]^{1 / \rho}
$$

Each individual has one unit of time and divides their time between market work denoted $h$, and non-market work $n=1-h$. Wages are denoted by $w_{g}$ for individual of gender $g$, and the household maximizes utility subject to the budget equation:

$$
c=w_{f} h_{f}+w_{m} h_{m}
$$

We can use this simple model to think about retirement by interpreting it as a model of lifetime choices rather than choices in a particular period. That is, one can think of the variable $h$ as measuring the length of the working life. While somewhat abstract, the simplicity of the model allows one to focus on two key forces in a very transparent setting: income effects and complementarity of non-market work times. 
To explore these forces quantitatively we carry out the following exercise. First, we choose parameters so that the model captures outcomes prior to the trend reversal in the mid 1990s. For our benchmark specification we consider the limiting case as $\gamma$ tends to unity so that family preferences are $\log \operatorname{linear}$ in $C$ and $N$. We normalize male wages to unity and set female wages equal to .80 . The preference parameter $\alpha$ cannot be determined separately from the scale of $a_{m}$ and $\alpha_{f}$ so we also normalize $a_{m}$ to unity. We will consider various values of $\rho$, but for each value of $\rho$ we will calibrate values for $\alpha$ and $\alpha_{f}$ to target the length of working lives for males and females. Assuming an adult lifetime of 60 years, we target values of $h_{m}=.7$ and $h_{f}=.5$ so that men work 40 percent more than women.

We now carry out three exercises. In the first exercise we simply increase $h_{f}$ exogenously from 0.5 to 0.6 . In subsequent exercises we will consider changes in fundamentals, but in this exercise we do not motivate why this increase happens and instead are simply asking what the optimal response of male working time would be in response to this exogenous increase.

In the second exercise we remove the gender gap between $a_{m}$ and $a_{f}$ by lowering $a_{f}$ to also equal unity. This is consistent with a story in which women devote more time to the market because the value of their time in home production becomes less valuable, thereby lowering the value they place on non-market time. And in the third exercise we remove both the gender gap between $a_{m}$ and $a_{f}$ as well as the gender gap in wages. In this third exercise men and women are perfectly symmetric and so the optimal household allocation will also be symmetric.

We carry out these exercises for values of $\rho$ in $[-10,0]$, and the results for $h_{m}$ 


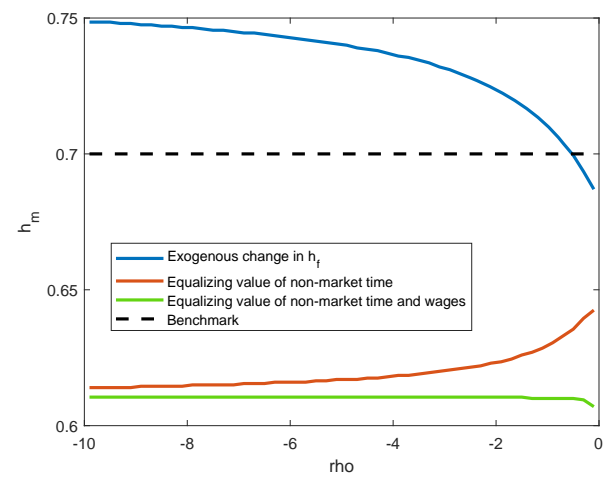

Figure 17: Effect of Female Work on Male Work

are shown in Figure 17.

Several patterns are worth noting. First, the blue line in the figure supports the intuition that if there is enough complementary between the non-working times of spouses, the effect of complementarity can more than offset the income effect, so that an exogenous increase in the working time of one spouse can lead to an increase in the working time of the other spouse. In fact, as the figure shows, the level of complementarity needed is somewhat modest, as $h_{m}$ increases as long as $\rho$ is below around -0.7 .

However, the figure shows that the results of this calculation do not necessarily translate into similar results when one attempts to generate the increase in the length of the working lives of females via changes in fundamentals. The red line in the figure shows that equalizing the values of $a_{m}$ and $a_{f}$ leads to a decline in the working life of males for all values of $\rho$ shown. Moreover, it is now the case that a more negative value of $\rho$ leads to a larger decline in the working life of males. In interpreting this result it is important to note that because each value 
of $\rho$ corresponds to a different calibration of the model, equalizing the values of $a_{m}$ and $a_{f}$ reflects a different magnitude of change in $a_{f}$. Rather than a "bug", we want to emphasize that this feature is actually an important element of the exercise. Specifically, if one wants to argue that complementarities are large and that this is why the increased market work of women is leading to greater market work of men, one has to reconcile this with the fact that there used to be large gaps between the two, which is to say that the gap between $a_{m}$ and $a_{f}$ must be dependent on $\rho$.

The green line in the figure shows the results when we remove all asymmetries between males and females. The result is a large drop in the working lives of men and a large increase in the working lives of women, with the effect being effectively independent of the value of $\rho$.

To be sure, these calculations are very crude. But we report them to highlight the fact that while the intuition about the effect of complementarities in nonmarket working time of spouses is compelling, the intuition does not necessarily translate so robustly to settings in which one models the endogeneity of all choices. 